\title{
Insoumises, de Conceição Evaristo: a tradução vista sob a lente de elementos paratextuais
}

\section{Insoumises, by Conceição Evaristo: the translation seen through the lens of paratextual elements}

\author{
Teresa Dias Carneiro* \\ Marcela lochem Valente ${ }^{* *}$
}

Resumo: Com sua escrita engajada e cheia de referências culturais específicas, a obra de Conceição Evaristo apresenta diversos desafios para a tradução. Insoumises (2016) - tradução da coletânea de contos Insubmissas lágrimas de mulheres (2011), para o francês, publicada pela editora Anacaona - traz muitos desses elementos relacionados à cultura afro-brasileira. Para a inteligibilidade do texto traduzido em seu contexto de recepção, os elementos paratextuais se mostram fundamentais. Embora no mercado editorial haja resistência ao uso de paratextos do tradutor, tais elementos se mostram não apenas como um espaço propício para dar voz ao tradutor, mas, sobretudo, como um espaço de alteridade. 0 foco da análise neste artigo será nos paratextos da obra e em alguns aspectos macroestruturais da tradução, em especial, o índice, a ordem de apresentação dos contos e as notas de rodapé, com base em Venuti (1996), Lambert e Van Gorp (1985), Genette (2009), Aixelá (2013) e Mittmann (2003).

Palavras-chave: Tradução; paratextos; Insoumises; Conceição Evaristo.

\footnotetext{
* Programa de Pós-Graduação em Estudos da Linguagem (PPGEL), Pontifícia Universidade Católica do Rio de Janeiro (PUC-Rio), e-mail: teresadcarneiro@ gmail.com.

** Programa de Pós-Graduação em Letras (PPGL), Universidade do Estado do Rio de Janeiro (UERJ), email: marcellaiv@ig.com.br.
} 
Abstract: With her engaging writing, full of culture-specific references, Conceição Evaristo's work presents various challenges to translation. Insoumises (2016) - the translation of the short-story collection Insubmissas lágrimas de mulheres (2011), by Conceição Evaristo, into French, published by Anacaona publisher - brings many of those items related to the Afro-American culture. Paratextual elements are of the essence for the intelligibility of the translated text in its context of reception. Although in the publishing market there is some resistance towards translator's paratexts, such elements are not only a space for the translator showing his/her voice, but also a space of alterity. The analytical focal point of this paper is the paratexts included in the work and some other macro structural translation aspects, mainly the table of contents, the order of presentation of the short stories and footnotes, based on Venuti (1996), Lambert and Van Gorp (1985), Genette (2009), Aixelá (2013) and Mittmann (2003).

Keywords: Translation; paratexts; Insoumises; Conceição Evaristo.

\section{Introdução}

Em um mundo globalizado em que conceitos como interculturalidade, multiculturalidade e transculturalidade são cada vez mais considerados e problematizados nas mais diferentes áreas e campos, o estudo da teoria do paratexto em tradução se torna cada dia mais necessário. Os paratextos se mostram, muitas vezes, como elementos fundamentais para a inteligibilidade de um texto traduzido em seu contexto de recepção, contribuindo para uma ética da diferença, tal qual proposta por Venuti (2002), e permitindo ao leitor da cultura de recepção um outro olhar sobre a cultura fonte que está sendo acessada através da tradução. Embora não seja objetivo do presente artigo definir e/ou problematizar os três termos supracitados, é relevante observar que tais conceitos trazem consigo a ideia de interação entre culturas, de multiplicidade, de superação de barreiras culturais que separam o "eu” do “outro”, “construindo uma predisposição para a leitura positiva, para uma multiplicidade cultural e social capaz de promover a reconstituição do próprio 
indivíduo" (FLEURI 2003, apud HINOJOSA; LIMA 2008: 3).

Embora haja certa resistência ao uso de paratextos do tradutor por inúmeras razões, dentre elas, o status ainda invisível esperado desse profissional (VENUTI 1996), tais elementos se mostram não apenas como um espaço para que o tradutor tenha voz, mas, principalmente, como um espaço de alteridade. Outro aspecto relevante a ser considerado é que, muitas vezes, elementos como notas de rodapé, por exemplo, podem aparecer como paratextos editoriais e não do tradutor. Segundo Wyler (2003), no Brasil, somos consumidores muito mais expressivos de obras traduzidas do que de literatura brasileira propriamente dita. Porém, "[a]pesar dessa presença maciça, o tradutor e seu trabalho permanecem 'invisíveis' aos olhos da maior parte da população do país" (WYLER 2003: 14). Com isso, muitas vezes, traduções são lidas como se tivessem sido escritas na própria língua e cultura de recepção e, como consequência disso, algumas vezes, para que a leitura seja facilitada ou até mesmo possibilitada, sem estranhamentos ao leitor da tradução, elementos da cultura de partida são excluídos, apagados, ignorados, domesticados.

Todavia, cabe ressaltar que, felizmente, nem todas as empresas do mercado editorial trabalham em consonância com essa prática e, segundo Britto (2007), muitas editoras têm percebido que boas traduções acabam resultando em aumento das vendas de livros, o que, além de despertar a atenção das editoras para a busca de tradutores que prestem um trabalho de qualidade, acaba por valorizar o trabalho do tradutor, levando ao reconhecimento de direitos autorais e, até mesmo, "possibilitando que [os tradutores] relatem as suas práticas, dificuldades e impressões do processo tradutório em prefácios, posfácios, notas e introduções da tradução" (FLORES; Hoff 2018: 353). Nesses espaços, que chamamos de paratextos, tradutores não só se tornam visíveis em seus trabalhos, mas ainda têm a oportunidade de valorizar e tornar compreensíveis elementos da cultura do "outro" possivelmente ininteligíveis aos leitores da cultura de recepção.

0 presente artigo tem como objetivo trazer algumas reflexões sobre questões relacionadas à tradução de Insubmissas lágrimas de mulheres (2011) para o francês, com o título de Insoumises (2016), de Conceição Evaristo, com foco em alguns elementos presentes na tradução para o contexto francófono 
como as notas de rodapé e alguns aspectos macroestruturais da tradução. A tradução da coletânea de contos Insubmissas lágrimas de mulheres (2011) foi publicada na França em dezembro de 2016 pela editora Anacaona, mesma editora que publicou L'histoire de Poncia (2015) e Banzo (2016), romances da escritora Conceição Evaristo.

\section{Conceição Evaristo além das barreiras nacionais}

Chegando ao contexto francófono através das traduções de quatro dos seus sete livros publicados no Brasil, a escritora afro-brasileira Conceição Evaristo vem alcançando cada vez mais visibilidade em sistemas literários no Brasil e no exterior. Após a publicação de L'histoire de Poncia, tradução de seu primeiro romance para a língua francesa, em março de 2015, pela editora Anacaona, com tradução de Paula Anacaona e Patrick Louis, lançado no Salão do Livro de Paris, a surpreendente acolhida da obra de Evaristo naquele contexto levou à publicação, pela mesma editora, de mais duas traduções de livros seus: seu segundo romance Becos da memória (2006), publicado pela editora Mazza, com duas edições posteriores pelas editoras Mulheres (2013) e Pallas (2017), cuja tradução publicada na França no início de 2016 recebeu o título Banzo: mémoires de la favela, traduzido por Paula Anacaona; e sua coletânea de contos Insubmissas lágrimas de mulheres, publicada pela editora Nandyala em 2011, com uma edição posterior pela editora Malê em 2016, mesmo ano da publicação da sua tradução francesa Insoumises, também com tradução de Paula Anacaona. Além das três traduções publicadas pela editora Anacaona, em 2019, sua coletânea de poemas Poemas da recordação e outros movimentos, publicada pela editora Nandyala em 2008 e pela editora Malê em 2017 recebeu também uma tradução para o francês e foi publicada em uma edição bilíngue pela editora Des Femmes-Antoinette Fouque em 2019, sob o título Poèmes de la mémoire et autres mouvements, traduzido por Rose Mary 
Osorio e Pierre Grouix.

$\mathrm{Na}$ França, a editora Anacaona surgiu a partir de "um pequeno projeto de levar obras alternativas às livrarias do seu país" (GUEDEs 2015: s.n.p.). 0 foco da editora é na tradução de literatura vista por eles como "marginal", ou seja, literatura não canônica e/ou não divulgada por grandes editoras em seus países de origem e que, por essa razão, dificilmente alcançariam projeção internacional, dadas as dificuldades de circulação e visibilidade. Porém, alguns autores publicados por grandes editoras em seus países de origem, como Rachel de Queiroz e José Lins do Rego, também fazem parte do catálogo da editora. Grande parte do catálogo da editora Anacaona é composto por obras selecionadas e traduzidas pela própria Paula Anacaona, editora, tradutora e dona da editora em questão. Conforme informações encontradas no site da própria editora ${ }^{1}$, em se tratando de literatura brasileira, o catálogo conta com três coleções: Urbana, Terra e Época. A Collection Urbana inclui nomes como Ferréz, Rodrigo Ciriaco, Plinio Marcos, Marcelino Freire, Fernando Molica e Luiz Carlos Soares. A Collection Terra traz autores como Conceição Evaristo, Maria Valeria Rezende, José Lins do Rego, Raimundo Carrero, Rachel de Queiroz e Jarid Arraes. E a chamada Collection Epoca leva para o contexto francófono autores como Djalma Ribeiro, Ana Paula Maia, Marçal Aquino, João Anzanello Carrascoza, Henrique Rodrigues e Helena Parente Cunha.

Embora Evaristo ainda não seja considerada parte do cânone da literatura brasileira, se considerarmos a noção monolítica e homogênea de cânone, "tido como um perene e exemplar conjunto de obras-primas representativas de determinada cultura local" (ZoLIN 2009: 327), definido geralmente pelo homem ocidental, branco, de classe média/alta, em posição de poder, a escritora vem circulando cada vez mais por esses espaços canônicos, sendo o maior dos exemplos disso a sua candidatura à cadeira de número 7, da Academia Brasileira de Letras ( $\mathrm{ABL}$ ), que esteve vaga por conta da morte do cineasta Nelson Pereira dos Santos em 21 de abril de 2018 e cujo patrono é Castro Alves. Segundo Evaristo:

O cânone é algo fixo, parado. Acho que quebrar as regras do cânone

\footnotetext{
${ }^{1}$ https://www.anacaona.fr/
} 
é muito difícil. Você pode encontrar um pesquisador ou outro que faça isso. As pessoas dizem às vezes que já sou canônica e eu não sei nem se quero ser canônica. Não sei se quero pertencer a esse cânone que está aí. Agora, acho que isso nos dá mais oportunidade de impor nossas vozes. De impor a voz da oralidade, que é intensa. (EVARISTO 2017).

Assim, embora "quebrar as regras" desse cânone imposto seja uma tarefa bastante difícil e desafiadora, nesse desejo de impor a sua voz afrofeminina na literatura brasileira, após grande comoção e apoio nas redes sociais e em alguns seguimentos da academia, assim como a repercussão na mídia da campanha \#ConceiçãoEvaristoNaABL, a escritora decidiu lançar a sua candidatura. Segundo ela "[s]e a academia brasileira é um lugar, uma instituição de representação de uma nacionalidade literária, então, estou com vontade de me candidatar mesmo e vamos ver" (EVARISTO 2018). Porém, apesar de uma das campanhas mais populares já feitas na $\mathrm{ABL}$, se não a mais popular, em 30 de agosto de 2018, o cineasta Cacá Diegues foi eleito com 22 votos, enquanto Conceição Evaristo recebeu apenas 1. Cabe lembrar aqui que, desde a fundação da $A B L$ em 1897, nenhuma mulher negra foi eleita como imortal para ocupar uma de suas 40 cadeiras. E, na verdade, em um olhar mais amplo, proporcionalmente poucas são as mulheres que ocupam ou já ocuparam tal posição. Daí toda a manifestação e a visibilidade gerada pela candidatura da escritora afro-brasileira.

Além da candidatura à $A B L$, Evaristo vem circulando cada vez mais por outros espaços que geralmente são reservados a escritores que fazem parte desse cânone que mencionamos anteriormente, gerando, muitas vezes, desconforto nesses espaços considerados lugares de visibilidade e prestígio. Em 2016 Evaristo recebeu um importante prêmio da literatura brasileira, o prêmio Jabuti, considerado um dos mais importantes prêmios literários do Brasil, concedido pela Câmara Brasileira do Livro, na categoria contos com seu livro Olhos d'água. E, em 2019, a escritora foi homenageada como personalidade literária do ano, pelo mesmo prêmio. No ano seguinte ao prêmio Jabuti, a escritora participou como convidada da Festa Literária Internacional de Paraty (FLIP); recebeu o prêmio Governo de Minas Gerais de Literatura na categoria Conjunto da Obra, sendo a primeira escritora negra a receber a premiação; 
recebeu o prêmio "Faz Diferença" do jornal O Globo, na categoria prosa; além de ter sido homenageada com a exposição Itaú Cultural, em São Paulo, na $34^{\text {a }}$ edição do programa Ocupação, que teve como tema "Ocupação Conceição Evaristo", "uma exposição dedicada a uma das vozes mais relevantes e necessárias da literatura brasileira contemporânea: a escritora mineira Conceição Evaristo" (ITAÚ CUltURAl 2017). Merecem destaque também as suas participações em diferentes edições do Salão do Livro de Paris, iniciadas em 2015 com o lançamento da tradução de Ponciá Vicêncio no contexto francófono, através da editora Anacaona.

Além das participações e dos prêmios de maior prestígio literário citados, Evaristo tem sido constantemente convidada como palestrante e escritora homenageada em inúmeras feiras e festivais literários nacionais e internacionais, como o Festival Literário de Araxá (2019), o Festival Literário de Iguape (2019), a Feira Literária de Betim (2018), a Festa Literária Internacional de Maringá (2018), apenas para citar alguns. Além dos festivais, em 2018, Conceição Evaristo foi a escritora homenageada no Exame Nacional do Ensino Médio (ENEM), tendo trechos de sua obra impressos nas provas; e, no ano seguinte, em 2019, a escritora foi também homenageada na $6^{\text {a }}$ edição da Olimpíada da Língua Portuguesa.

Por último, mas não menos importante, Conceição Evaristo vem participando com bastante frequência de eventos acadêmicos e literários no Brasil e no exterior, com destaque para a sua atuação na França e nos Estados Unidos, por conta das traduções de parte da sua obra para as línguas inglesa e francesa e da acolhida muito positiva, principalmente por parte da academia, em ambos os países. Ademais, a escritora tem ainda participado de programas de rádio e televisão voltados à educação, novelas, programas de entrevistas, além de possuir inúmeras entrevistas publicadas em diferentes fontes na internet. Um exemplo que gostaríamos de citar é a entrevista concedida em julho de 2017 à rádio francesa $\mathrm{RFI}$, uma rádio de notícias que transmite para o mundo todo em francês e em outros 14 idiomas, com suas redações localizadas em Paris e a uma rede de 400 correspondentes espalhados pelos cinco continentes. 


\section{Insubmissas lágrimas de mulheres}

Insubmissas lágrimas de mulheres é uma coletânea composta por 13 contos, que têm como protagonistas mulheres negras. Em cada um dos contos, vozes-mulheres falam sobre suas dores, temores, desejos, e sobre sua necessidade constante de inventar novos modos de (sobre)vivência e resistência. Empatia, sensibilidade e sororidade são algumas características comuns na escrita de Evaristo, marcada por sua escrevivência afrofeminina e por seu lugar de fala, sempre claramente enunciado.

O livro inicia com uma abertura onde, antes da apresentação do primeiro conto, a narradora-personagem alerta sobre a veracidade das histórias ali contadas, baseadas nas experiências das mulheres negras entrevistadas, assim como em aspectos de sua própria vivência.

Gosto de ouvir, mas não sei se sou hábil conselheira. Ouço muito. Da voz outra, faço a minha, as histórias também. $E$, no quase gozo da escuta, seco os olhos. Não os meus, mas de quem conta. $E$, quando de mim uma lágrima se faz mais rápida do que o gesto de minha mão a correr sobre o meu próprio rosto, deixo o choro viver. E, depois, confesso a quem me conta, que emocionada estou por uma história que nunca ouvi e nunca imaginei para nenhuma personagem encarnar. Portanto, estas histórias não são totalmente minhas, mas quase que me pertencem, na medida em que, às vezes, se (com)fundem com as minhas. Invento? Sim, invento, sem o menor pudor. Então, as histórias não são inventadas? Mesmo as reais, quando são contadas. Desafio alguém a relatar fielmente algo que aconteceu. (...) Entretanto, afirmo que, ao registrar estas histórias, continuo no premeditado ato de traçar uma escrevivência. (EVARISTO 2011: 11)

Parte dos contos apresentados é escrita em primeira pessoa com o intuito de destacar o momento do encontro entre a personagem-narradora e as personagens entrevistadas que dão vida a cada um dos capítulos. Porém, ao longo da narrativa, as vozes dessas mulheres ganham destaque e o seu protagonismo é percebido. Em alguns outros contos a narrativa mescla vozes, marcando a presença da personagem-narradora, porém deixando as mulheres protagonistas em primeiro plano todo o tempo. Cada conto retrata dores, violências e humilhações sofridas diariamente pelas mulheres negras na 
sociedade brasileira. Apesar de histórias fortes, impactantes, muitas delas até mesmo assustadoras, Insubmissas lágrimas de mulheres é uma sensível obra que ressalta a delicadeza e o cuidado da escrita de Evaristo através dos diversificados retratos apresentados: mulheres da cidade, mulheres do campo, solteiras, casadas, lésbicas, sonhadoras, solitárias, jovens, meninas, mulheres experientes que, apesar da diversidade de suas subjetividades, estão ligadas pela condição de ser mulher negra no Brasil e suas implicações.

Além da breve abertura, o livro é composto por 13 contos que apresentam uma certa unidade temática e cujas histórias são reunidas pela personagem-narradora. Essa personagem visita as protagonistas, ouve suas histórias e depois as compartilha com o leitor através dos contos. Cada capítulo do livro, ou cada conto, traz como título o nome da protagonista da história narrada.

\section{Elementos paratextuais no texto traduzido 4.1 Comentários gerais sobre a edição traduzida}

Iniciando a nossa observação a partir de aspectos macroestruturais em Insubmissas lágrimas de mulheres e sua tradução para a língua francesa, observaremos alguns aspectos como a divisão do texto e os títulos de capítulos e seções.

José Lambert e Hendrik Van Gorp propuseram um modelo para o estudo descritivo de traduções literárias através de uma abordagem funcional e sistêmica. Em seu texto “On Describing Translations” (1985), os autores argumentam que, para que as pesquisas sobre tradução sejam mais relevantes de um ponto de vista teórico e também histórico, é necessário esboçar uma metodologia para estudar vários aspectos relacionados à tradução. No modelo prático para análise textual proposto pelos autores e elaborado a partir das pesquisas descritivas desenvolvidas por eles, Lambert e Van Gorp apontam para a existência de quatro diferentes níveis de análise em sua metodologia: a 
análise dos dados preliminares que inclui a observação de títulos, paratextos (capa, orelhas, nome do autor e tradutor etc.), metatextos (prefácios, ensaios, críticas); o trabalho no nível macroestrutural, que busca verificar as divisões do texto, títulos de capítulos e seções, estrutura narrativa e estratégia global da tradução; o nível microestrutural que cuida da seleção vocabular, das estruturas gramaticais, do tipo de narrativa, e de aspectos como modalização, registros, etc.; e o contexto sistêmico. É relevante ressaltar que, para os autores, o modelo proposto não deve ser aplicado em sua totalidade. Ele apenas aponta aspectos que podem ser analisados em trabalhos cujo objetivo central seja o estudo de traduções literárias.

Considerando então o primeiro aspecto aqui proposto no presente artigo, a divisão do texto em Insubmissas lágrimas de mulheres (2011) e Insoumises (2016) se apresenta da seguinte forma:

Quadro 1 - Índice no texto de partida e na tradução

\begin{tabular}{|c|c|}
\hline $\begin{array}{c}\text { Insubmissas lágrimas de mulheres } \\
\text { (Nandyala } 2011 \text { / Malê 2016) }\end{array}$ & $\begin{array}{c}\text { Insoumises } \\
\text { (Anacaona 2016) }\end{array}$ \\
\hline 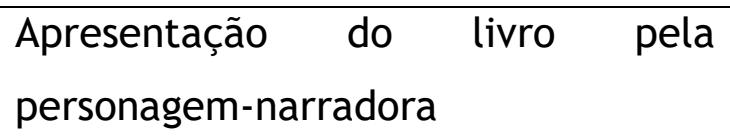 & $\begin{array}{l}\text { Apresentação do livro } \\
\text { personagem-narradora }\end{array}$ \\
\hline 1. Aramides Florença & 1. Isaltina Campo Belo \\
\hline 2. Natalina Soledad & 2. Aramides Florença \\
\hline 3. Shirley Paixão & 3. Natalina Soledad \\
\hline 4. Adelha Santana Limoeiro & 4. Shirley Paixão \\
\hline $\begin{array}{l}\text { 5. Maria do Rosário Imaculada dos } \\
\text { Santos }\end{array}$ & $\begin{array}{l}\text { 5. Maria du Rosaire Immaculée dos } \\
\text { Santos }\end{array}$ \\
\hline 6. Isaltina Campo Belo & 6. Mary Benedita \\
\hline 7. Mary Benedita & 7. Mirtes Aparecida Da luz \\
\hline 8. Mirtes Aparecida Daluz & 8. Adelha Santana Limoneiro \\
\hline 9. Líbia Moirã & 9. Libia Moirã \\
\hline 10. Lia Gabriel & 10. Lia Gabriel \\
\hline 11. Rose Dusreis & 11. Rose Dusreis \\
\hline 12. Saura Benevides Amarantino & 12. Saura Benevides Amarantino \\
\hline
\end{tabular}




\begin{tabular}{|l|l|}
\hline 13. Regina Anastácia & 13. Régina Anastacia \\
\hline
\end{tabular}

Elaboração: as autoras

Logo de início percebemos que o índice, que em ambas as edições brasileiras encontra-se antes da apresentação do livro pela personagemnarradora, na versão francesa foi deslocado para o final do livro, após o conto "Régina Anastacia", como "Table des matières", o que é norma geral nas edições francesas. Falando da divisão do texto propriamente dita, observamos que as edições da editora Nandyala de 2011 e da editora Malê de 2016 mantêm exatamente a mesma ordem para os contos apresentados. Porém, nos chama a atenção o fato que a versão francesa da editora Anacaona tenha optado por alterar a ordem dos contos. É importante ressaltar que os contos não são enumerados em nenhuma das edições publicadas. Porém, apenas para fins didáticos, apresentamos uma tabela enumerada para que visualizemos com mais facilidade as alterações observadas na versão francesa.

O conto que abre a versão francesa é "Isaltina Campo Belo", que aparece apenas como o sexto conto nas edições brasileiras. A edição francesa segue então a sequência dos três primeiros contos apresentados nas edições brasileiras. Porém, logo em seguida, observamos mais uma alteração. 0 quarto conto das edições brasileiras, "Adelha Santana Limoeiro", é deslocado para a posição de conto de número oito na versão francesa. Seguindo, o conto de número cinco coincide em ambas as edições, porém, como o sexto conto apresentado nas edições brasileiras já havia sido deslocado para a posição de primeiro conto na edição francesa, temos uma nova alteração na ordem de apresentação. Em seguida, os contos apresentados como sétimo e oitavo contos das edições brasileiras, "Mary Benedita” e "Mirtes Aparecida Daluz", aparecem como sexto e sétimo contos na versão francesa, seguidos, em francês, do conto "Adelha Santana Limoneiro", que ocupava a posição de número quatro nas edições em português. A partir daí, percebemos que os contos seguem a mesma ordem nas edições brasileiras e francesa. Assim, observamos que apenas o conto de número cinco e os contos de nove a doze permanecem na mesma posição no texto de partida e na tradução francesa.

Voltando o nosso olhar para os nomes das personagens que intitulam cada 
capítulo, percebemos que nove dos treze nomes não foram traduzidos ou alterados. Apenas quatro dos nomes apresentam alterações: "Adelha Santana Limoeiro", que se torna "Adelha Santana Limoneiro"; "Maria do Rosário Imaculada dos Santos" apresentado na versão francesa como "Maria du Rosaire Immaculée dos Santos"; "Mirtes Aparecida Daluz", que na versão francesa é "Mirtes Aparecida Da luz"; e "Regina Anastácia", que ficou "Régina Anastacia" na tradução para o francês.

Percebe-se que a alteração mais significativa foi a do primeiro conto do volume. A decisão editorial de apresentar, na edição francesa, em primeiro lugar o conto "Isaltina Campo Belo" e não "Aramides Florença" causa bastante impacto na recepção deste volume de histórias sobre mulheres. Isaltina é uma personagem lésbica, ao contrário de Aramides, que é heterossexual. 0 que as aproxima é que ambas sofrem estupro, a primeira por cinco homens desconhecidos, a segunda, pelo próprio marido. 0 que poderia explicar essa decisão editorial? Iniciar os contos com uma personagem lésbica pode chamar a atenção para a questão de gênero, um tema central na literatura contemporânea. Nos cinco anos transcorridos entre a publicação dos contos no Brasil (2011) e na França (2016), a questão de gênero migrou paulatinamente para o centro da temática literária contemporânea. A tradutora/editora da edição francesa pode ter querido ressaltar isso, tomando a liberdade de alterar a ordem dos contos, uma decisão editorial que demonstra o protagonismo e a agentividade dessa tradutora/editora.

\subsection{As notas de tradutor}

Um outro elemento que consideramos ser de fundamental importância no texto traduzido é a presença de notas, sejam elas do tradutor ou editoriais. De acordo com o modelo metodológico proposto por Lambert e Van Gorp, a análise dos dados preliminares de uma tradução inclui a observação de elementos como títulos, paratextos e metatextos. $\mathrm{E}$ as notas, tanto do tradutor quanto as editoriais, merecem ser observadas, pois podem funcionar como uma 
forma de explicar "o outro" para a cultura de recepção.

As notas de rodapé em Insoumises não são caracteristicamente notas de tradutor, que, na França, aparecem com as seguintes siglas: "NDT" (Note du Traducteur), em caixa alta, ou em caixa alta e baixa ("NdT") ou ainda em caixa baixa ("ndt"). Vê-se ainda a derivação "NDLT" (Notes da la Traductrice), quando se trata de uma tradutora do sexo feminino.

As notas de tradutor, de modo geral, aparecem mais comumente no rodapé, no final de capítulo ou de volume. No caso do livro sob análise, elas são todas de rodapé, mas sem a distinção de serem do tradutor, no caso, da tradutora, Paula Anacaona. Como Anacaona é também a editora, poderíamos encarar as notas de rodapé na edição como sendo Notas do Editor, mas também essa distinção não é feita. Assim sendo, vamos analisar as notas como sendo da tradutora, mas já sabendo que, como ela também é editora, algumas das questões que se apresentam como restritivas aos tradutores na apresentação de notas pelas editoras, neste caso, não se apresentam ou se apresentam de outra forma, numa espécie de diálogo ou embate entre as duas funções de Anacaona como editora e tradutora. Neste caso, a agentividade da tradutora é mais alargada em relação à agentividade tradicional dos tradutores, sendo que suas decisões de (i) apor notas, (ii) quantas notas, (iii) em que momentos do texto e (iv) com qual conteúdo podem advir de decisões editoriais tomadas para o conjunto de edições das traduções de obras de Conceição Evaristo pela casa editora. De fato, L'Histoire de Poncia (2015) e Banzo mémoires de la favela (2016) também trazem notas de rodapé de conteúdo semelhante e algumas até mesmo idênticas.

Em sua obra fundacional para a teoria do paratexto, Seuils (1987), traduzida no Brasil com o título Paratextos editoriais (2009), Gérard Genette não faz menção específica às notas de tradutor, mas discorre sobre as notas em geral. Sua definição de nota é a seguinte:

Uma nota é um enunciado de tamanho variável (basta uma palavra) relativo a um segmento mais ou menos determinado de um texto, e disposto seja em frente seja como referência a esse segmento. 0 caráter sempre parcial do texto de referência e, consequentemente, o caráter sempre local do enunciado colocado em nota, parece-me ser o traço formal que melhor distingue esse elemento de paratexto 
e que o opõe, entre outros, ao prefácio - inclusive aos prefácios ou posfácios que, modestamente, se intitulam "Nota", como ocorre com frequência em Conrad. (GENETTE 2009: 281)

0 autor ressalta ainda que o aparato das notas, apesar de se distinguir do prefácio por seu caráter sempre local e parcial, estabelece uma "relação muito estreita de continuidade e de homogeneidade" com ele (GENETTE 2009: 282). Essa afirmação poderia ser estendida para se dizer que, na verdade, todos os elementos paratextuais em uma edição dialogam entre si, principalmente aqueles característicos dos livros traduzidos, com seus elementos distintivos (prefácio/posfácio do tradutor, notas do tradutor, posição e destaque do nome do tradutor na edição, menções ao tradutor ou à tradução em outros elementos paratextuais como prefácios do editor, alógrafos ou de encomenda, textos de orelhas e quarta capa etc.) confirmando as decisões editoriais a respeito de dar destaque ao tradutor e à tradução ou empreender o apagamento de ambos (CARNeIRO 2014).

Genette afirma ainda que o destinatário da nota é, em princípio, o leitor e que a nota é de leitura facultativa, podendo endereçar-se, na prática, a leitores especiais, que se interessam pelo complemento de informação ali apresentado (GENETTE 2009: 285). Nas notas autorais, constam definições ou explicações de termos usados no texto, traduções de citações produzidas no texto em língua original (ou o inverso), referências de citações, indicações de fontes, exibição de autoridades de apoio, de informações ou de documentos confirmativos e complementares, detalhamentos de um fato evocado no texto de forma mais vaga ou sóbria, menções de incertezas ou complexidades negligenciadas no texto, argumentos complementares, apartes autobiográficos etc. (GENETTE 2009: 286-288). As notas autorais, para Genette, podem ser encaradas muitas vezes como sendo parte do texto e não constituindo um paratexto propriamente dito, como se fossem um derramamento do texto para um fora-do-texto. Já as notas alógrafas (e nessa classificação para ele estão incluídas as notas de tradutor), ele diz serem de caráter editorial - ou advindas de decisões editoriais -, posteriores às notas autorais e consistindo de comentários exteriores, com função principal de esclarecimento e de 
informação. São consideradas pelo autor como tipicamente pertencentes ao paratexto (GENETTE 2009: 301). Como Genette não faz considerações específicas ao paratexto do livro traduzido, é preciso investigar o que teóricos e pesquisadores dos Estudos da Tradução dizem a respeito da nota de tradutor.

Em primeiro lugar, é importante ressaltar que alguns autores incluem a nota de tradutor nos procedimentos ou estratégias tradutórios. Em Procedimentos técnicos da tradução (1990), Heloisa Barbosa inclui a nota de tradutor no rodapé no procedimento de "Transferência com explicação". Segundo a autora, lança-se mão desse procedimento quando o tradutor infere que o leitor não será capaz de entender o que está sendo dito no texto de partida através do contexto, tendo a nota a função precípua de "proporcionar ao leitor um entendimento do significado do mesmo [do termo]" (BARBOSA 1990: 74). Barbosa acrescenta ainda que essa explicação pode se dar em notas de rodapé ou explicações diluídas no texto. A segunda estratégia seria usada para se evitar o emprego da nota de rodapé e pode aparecer entre vírgulas, travessões, aspas ou parênteses. Em sua proposta de categorização dos procedimentos da tradução, a autora classifica o procedimento mencionado nos casos de divergência da realidade extralinguística. Caberia, pois, ao tradutor decidir se o complemento de informação ou esclarecimento seria apresentado em nota destacada do texto ou diluído no texto.

Javier Franco Aixelá, em sua classificação de estratégias tradutórias para itens culturais específicos (ICE) com base no grau de manipulação intercultural, inclui as notas de rodapé na estratégia denominada "Explicação extratextual". Assim sendo, o autor apresenta a seguinte explicação:

O tradutor (...) considera necessário oferecer alguma explicação do significado ou implicação do ICE. Ao mesmo tempo, não parece legítimo ou conveniente misturar esta explicação com o texto. A decisão, então, é distinguir o comentário indicando-o (nota de rodapé, nota de fim, glossário, comentário/tradução entre parênteses em itálico etc.). (IXELÁ 2013: 198)

É importante destacar que Aixelá subdivide as estratégias tradutórias de itens culturais específicos em dois grupos segundo sua natureza conservativa ou substitutiva, isto é, pela conservação das referências culturais no texto de 
chegada ou por sua substituição por referências mais próximas do polo receptor (AIXELÁ 2013: 196). No caso da explicação extratextual, ela está incluída no grupo das estratégias conservativas. Portanto, quando o tradutor chama uma nota de rodapé, ele está conservando a referência cultural do polo de partida, explicando-a no polo de chegada. Essa caracterização é especialmente relevante de se guardar em mente quando estivermos analisando as notas de rodapé de Insoumises, ligadas maciçamente à explicação de itens culturais específicos brasileiros.

Apesar de ser um procedimento ou estratégia facultado ao tradutor, na prática, pode ser um recurso coibido pelas editoras, principalmente as de livros comerciais ou de ficção de massa, como se vê no Manual da Sextante.

\begin{abstract}
Nota do tradutor
Evitar ao máximo a utilização desse recurso. Se a tradução do termo ou expressão for curta, fornecê-la entre parênteses. Caso contrário, redigi-la na sequência do texto como se fosse parte do original. Em ambos os casos, indicar em relatório à parte o termo ou expressão traduzidos, fornecendo os números das páginas no original estrangeiro e na tradução.

Quando for realmente necessário inserir “nota do tradutor”, usar asterisco e a indicação N. do T. (em itálico). (SEXTANTE: 2)
\end{abstract}

De qualquer forma, a existência ou não de notas de tradutor em uma edição não é uma decisão apenas do tradutor, mas uma decisão editorial. Mesmo que um tradutor tenha desejado chamar uma nota, ela pode ser retirada por decisão do editor. Mas por que as editoras teriam resistência a notas de tradutor?

No campo teórico da tradução, de modo geral, há duas perspectivas principais em relação às notas de tradutor. Na primeira perspectiva, que se mostra resistente à existência da nota de tradutor, alegando que atrapalha a leitura, a sua existência só se justifica como um recurso auxiliar à compreensão do leitor, "recurso para resolver problemas de tradução que não foram resolvidos no próprio texto, servindo então como instrumento facilitador da leitura do texto da tradução, já que se supõe que ela esclareça o sentido" (MitTmann 2003: 118). Constituiriam, assim, um acréscimo apenas permitido para reconstituir melhor o significado contido no texto "original". Não haveria, 
portanto, espaço para a manifestação da subjetividade do tradutor nas notas. Essa perspectiva se alinha a uma concepção mais essencialista da linguagem, em que a tradução é transporte de significados e, portanto, o tradutor ocupa uma posição hierárquica subalterna à do autor, detentor desse significado, sendo o tradutor um mero decodificador. É claro que nessa perspectiva qualquer intervenção do tradutor no texto traduzido e na edição é encarada com desconfiança e como desnecessária.

Já na segunda perspectiva, de teóricos mais alinhados a uma abordagem pós-estruturalista da tradução, encaram-se as notas de tradutor como um lugar privilegiado para expor pistas ou falar claramente do processo tradutório, em que o tradutor pode se colocar como produtor de significados, responsável por uma leitura que the é própria. De modo geral, as editoras mais comerciais alinham-se à primeira perspectiva, por não quererem chamar a atenção para a figura do tradutor e para o fato de que aquele livro é uma tradução, mantendo a ilusão do leitor de que está lendo um original. No caso de Insoumises, como a tradutora também é editora, ela teve liberdade para inserir as notas julgadas adequadas.

Dawn Alexis Duke se alinha à segunda perspectiva, defendendo que as notas são uma forma de participação ativa e decisiva na criação de um outro texto, o texto traduzido.

Diferentemente das abordagens teóricas afiliadas ao logocentrismo, apresentamos a N. do T. como um espaço textual, aberto, multiforme, diversificado e livre, disponível para quem pratica a tradução. Trata-se de uma forma flexível de atuação que complementa a ação transformadora do tradutor. (DUKE 1993: 6)

Assim sendo, enquanto os teóricos alinhados à primeira perspectiva assumem uma postura contrária às notas de tradutor, a segunda as estimula, por entendê-las como explicitantes do processo tradutório do tradutor em seu papel ativo de interpretante do texto de partida, em constante diálogo com ele, e de produtor textual.

Mittmann (2003), analisando as notas de tradutor à luz da Análise do Discurso, apresenta-as como um "discurso de extensão": 
(...) consideramos que a N.T. materializa o discurso do tradutor produzido durante o processo tradutório. Na verdade, trata-se de um mesmo processo de produção de discursos, o processo tradutório, um mesmo sujeito enunciador, o tradutor, mas dois discursos diferentes, um dependente do outro: o discurso da N.T. só existe a partir do discurso da tradução. Não chegamos a dizer que se trata de um discurso paralelo, como diz Orlandi, mas um discurso de extensão, produzido durante o mesmo processo, embora com peculiaridades que diferem do discurso que the serve de base. (MITTMANN 2003: 128129)

Mittmann (2003), na análise do seu corpus de notas de tradutor, dividiuas segundo três recortes. No primeiro, estão as notas em que há uma "nãocoincidência entre o tradutor e o autor" (p. 135), ou de uma heterogeneidade mostrada (p. 137), em que o tradutor assume uma posição que não é de mero explicador do texto traduzido, mas especifica uma visão externa ao texto. No segundo, estão as notas em que o tradutor recorre a outros discursos (p. 135), como referências a dicionários, obras de temas específicos, enciclopédias etc., como forma de dar sustentação ao seu discurso (p. 145). No terceiro, estão as notas "em que o tradutor manifesta a falta de palavras, a multiplicidade de sentidos e suas incertezas durante o processo tradutório” (p. 135), como quando o tradutor não encontra na língua de chegada uma expressão equivalente à do texto de partida. Tendo em vista que há um bordão muito difundido entre os críticos de tradução (e aceito por alguns tradutores) de que "na nota de rodapé, o tradutor passa recibo de sua incompetência", nas notas desse recorte, “o tradutor, por sua vez, costuma culpar a língua pela falta” (p. 155).

Após apresentar algumas perspectivas variadas, dentro e fora dos Estudos da Tradução, numa breve recuperação teórica sobre as notas de tradutor, sem a pretensão de esgotar a apresentação de todas as abordagens existentes ao tema, passaremos então a analisar as notas contidas em Insoumises.

\subsection{As notas de rodapé em Insoumises (2016)}

Vejamos abaixo um quadro recuperando as notas de Insoumises a partir 
do trecho do texto ao qual estão ligadas, com suas respectivas traduções em português, feitas pelas autoras deste artigo.

Quadro 2 - Notas de rodapé em Insoumises

\begin{tabular}{|c|c|c|c|c|}
\hline Pág. & Trecho do texto & $\begin{array}{l}\text { Referência } \\
\text { no texto }\end{array}$ & Nota de rodapé & Tradução \\
\hline 45 & $\begin{array}{l}\text { Je respectai son } \\
\text { silence, imaginant } \\
\text { une saudade }{ }^{1} \\
\text { contenue et une } \\
\text { incompréhension } \\
\text { face à la mort de } \\
\text { sa mère. }\end{array}$ & saudade & $\begin{array}{l}\text { Souvenir nostalgique } \\
\text { et tendre, } \\
\text { mélancolique, } \\
\text { accompagné d'un } \\
\text { sentiment de de } \\
\text { "manque habité". }\end{array}$ & $\begin{array}{l}\text { Lembrança nostálgica } \\
\text { e terna, melancólica, } \\
\text { acompanhada de um } \\
\text { sentimento de "falta } \\
\text { enraizada". }\end{array}$ \\
\hline 126 & $\begin{array}{l}\text { Mon arrière- } \\
\text { grand-père } \\
\text { paternel était le } \\
\text { fils naturel du } \\
\text { coronel }{ }^{1} \text { Fontes } \\
\text { dos Reis Menezes } \\
\text { et de Filomena, } \\
\text { son esclave de } \\
\text { maison et mère de } \\
\text { lait noire de ses } \\
\text { enfants. }\end{array}$ & coronel & $\begin{array}{l}\text { Titre honorifique } \\
\text { donné aux grands } \\
\text { propriétaires terriens } \\
\text { ou aux hommes } \\
\text { importants d' de } \\
\text { l'intérieur du Brésil, } \\
\text { sans rapport avec la } \\
\text { hiérarchie militaire. }\end{array}$ & $\begin{array}{l}\text { Título honorífico dado } \\
\text { aos grandes } \\
\text { proprietários de terra } \\
\text { ou aos homens } \\
\text { importantes r do } \\
\text { interior do Brasil, sem } \\
\text { relação com a } \\
\text { hierarquia militar. }\end{array}$ \\
\hline 143 & $\begin{array}{l}\text { «Mon nom é } \\
\text { Régina } \\
\text { Anastacia }{ }^{1} . \text { " }\end{array}$ & Anastacia & $\begin{array}{l}\text { Anastacia, esclave } \\
\text { africaine du } 18^{e} \\
\text { siècle d'une grande } \\
\text { beauté, refusa les } \\
\text { avances sexuelles de } \\
\text { son maître. En guise } \\
\text { de punition, elle fut } \\
\text { forcée de porter un } \\
\text { masque de Flandres } \\
\text { pendant toute sa vie. } \\
\text { Défigurée, elle } \\
\text { mourut dans } \\
\text { d'horribles } \\
\text { souffrances. Elle est } \\
\text { vénérée au Brésil et } \\
\text { en Afrique. }\end{array}$ & $\begin{array}{l}\text { Anastácia, escrava } \\
\text { africana do século } \\
\text { XVIII de grande beleza, } \\
\text { se recusou a ceder aos } \\
\text { avanços sexuais de seu } \\
\text { dono. Como punição, } \\
\text { foi forçada a usar uma } \\
\text { máscara de latão } \\
\text { (máscara de flandres) } \\
\text { a vida toda. } \\
\text { Desfigurada, morreu } \\
\text { em terrível } \\
\text { sofrimento. } \\
\text { venerada no Brasil e na } \\
\text { África. }\end{array}$ \\
\hline \multirow[t]{3}{*}{144} & \multirow{3}{*}{ 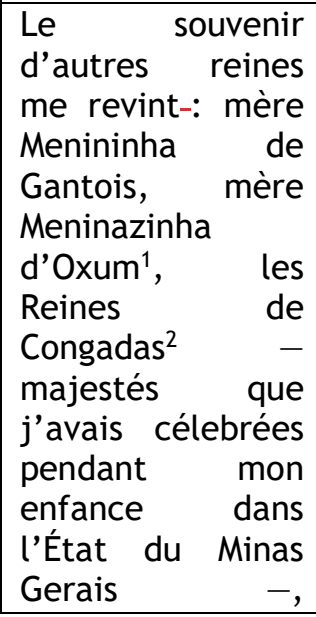 } & $\begin{array}{c}\text { mère } \\
\text { Menininha de } \\
\text { Gantois, } \\
\text { mère } \\
\text { Meninazinha } \\
\text { d'Oxum }\end{array}$ & $\begin{array}{lr}\text { Mères de } & \text { saint, } \\
\text { prêtresses dans la } \\
\text { religion } & \text { afro- } \\
\text { brésilienne. } & \end{array}$ & $\begin{array}{lr}\text { Mães de } & \text { santo, } \\
\text { sacerdotisas } & \text { na } \\
\text { religião } & \text { afro- } \\
\text { brasileira. } & \end{array}$ \\
\hline & & Congadas & $\begin{array}{l}\text { La congada est un } \\
\text { spectacle culturel et } \\
\text { religieux afro- } \\
\text { brésilien, composé de } \\
\text { chants et de danses, } \\
\text { représentant le } \\
\text { couronnement d'un } \\
\text { roi du Congo. } \\
\end{array}$ & $\begin{array}{l}\text { A congada é um } \\
\text { espetáculo cultural e } \\
\text { religioso afro- } \\
\text { brasileiro, composto } \\
\text { de cantos e danças, } \\
\text { representando a } \\
\text { coroação de um rei do } \\
\text { Congo. }\end{array}$ \\
\hline & & Clementina & Trois chanteuses & Três cantoras afro- \\
\hline
\end{tabular}




\begin{tabular}{|c|c|c|c|c|}
\hline & \multirow{2}{*}{$\begin{array}{l}\text { Clementina de } \\
\text { Jésus, Dona Ivone } \\
\text { Lara, Lia de } \\
\text { Itamaracá }{ }^{3} \text { Lea } \\
\text { Garcia, Ruth de } \\
\text { Souza }{ }^{4} \text { madame } \\
\text { Laurinda } \\
\text { Natividade, la } \\
\text { professeure } \\
\text { Efigenia Carlos, } \\
\text { dona Iraci } \\
\text { Graciano Fidelis, } \\
\text { Toni Morrison, } \\
\text { Nina Simone... }\end{array}$} & $\begin{array}{l}\text { de Jésus, } \\
\text { Dona Ivone } \\
\text { Lara, Lia de } \\
\text { Itamaracá } \\
\end{array}$ & $\begin{array}{l}\text { afro-brésiliennes et } \\
\text { revendiquant } \\
\text { fortemente leur } \\
\text { héritage. }\end{array}$ & $\begin{array}{ll}\text { brasileiras } & \text { que } \\
\text { reivindicam } & \\
\text { fortemente } & \text { sua } \\
\text { herança. } & \\
\end{array}$ \\
\hline & & $\begin{array}{l}\text { Lea Garcia, } \\
\text { Ruth de } \\
\text { Souza }\end{array}$ & $\begin{array}{lr}\text { Deux actrices afro- } \\
\text { brésiliennes, faisant } \\
\text { figure } & \text { de } \\
\text { précurseurs. } & \end{array}$ & $\begin{array}{l}\text { Duas atrizes afro- } \\
\text { brasileiras tidas como } \\
\text { precursoras. }\end{array}$ \\
\hline \multirow[t]{4}{*}{146} & \multirow{5}{*}{$\begin{array}{l}\text { Invoquant, selon } \\
\text { leur foi, Zambi, } \\
\text { Olorum }{ }^{1}, \quad \text { Exu, } \\
\text { Ogum }^{2}, \quad \text { Notre- } \\
\text { Dame du Rosaire }{ }^{3} \text {, } \\
\text { saint Benoît }{ }^{4} \text { et le } \\
\text { petit Jésus, ou } \\
\text { sainte Iphigénie }{ }^{5} \\
\text { - ils demandaient } \\
\text { à leurs } \\
\text { protecteurs, } \\
\text { séparément ou } \\
\text { tous ensemble, le } \\
\text { chemin menant à } \\
\text { la liberté du } \\
\text { camps d'esclaves } \\
\text { marrons. }\end{array}$} & $\begin{array}{l}\text { Zambi, } \\
\text { Olorum }\end{array}$ & $\begin{array}{l}\text { Dans les cultes } \\
\text { brésiliens d'origine } \\
\text { africaine, Zambi et } \\
\text { Olorum, sous deux } \\
\text { noms différents, } \\
\text { représentent l'être } \\
\text { supérieur, le } \\
\text { créateur des orixas } \\
\text { (divinités) et de } \\
\text { l'Homme. }\end{array}$ & $\begin{array}{l}\text { Nos cultos brasileiros } \\
\text { de origem africana, } \\
\text { Zumbi e Olorum, sob } \\
\text { dois nomes diferentes, } \\
\text { representam o ser } \\
\text { superior, o criador dos } \\
\text { orixás (divindades) e } \\
\text { do Homem. }\end{array}$ \\
\hline & & Exu, Ogum & $\begin{array}{l}\text { Orixas (divinités } \\
\text { afro-brésiliennes). }\end{array}$ & $\begin{array}{l}\text { Orixás (divindades } \\
\text { afro-brasileiras). }\end{array}$ \\
\hline & & $\begin{array}{l}\text { Notre-Dame } \\
\text { du Rosaire }\end{array}$ & $\begin{array}{l}\text { Sainte vénérée par } \\
\text { les esclaves et } \\
\text { devenue leur } \\
\text { protectrice. }\end{array}$ & $\begin{array}{l}\text { Santa venerada pelos } \\
\text { escravos e que se } \\
\text { tornou sua protetora. }\end{array}$ \\
\hline & & saint Benoît & $\begin{array}{l}\text { Saint Noir, d'origine } \\
\text { incertaine mais très } \\
\text { probablement } \\
\text { africaine } \\
\text { (éthiopienne) et } \\
\text { vénéré par les } \\
\text { esclaves et leurs } \\
\text { descendants. }\end{array}$ & $\begin{array}{l}\text { Santo negro, de } \\
\text { origem incerta, mas } \\
\text { muito provavelmente } \\
\text { africana (etíope) e } \\
\text { venerado } \\
\text { escravos e pelos } \\
\text { descendentes. }\end{array}$ \\
\hline 147 & & $\begin{array}{c}\text { sainte } \\
\text { Iphigénie }\end{array}$ & $\begin{array}{l}\text { Sainte Noir, fille du } \\
\text { roi d'Ethiopie, } \\
\text { vénérée par les } \\
\text { esclaves et leurs } \\
\text { descendants. }\end{array}$ & $\begin{array}{lrr}\text { Santa negra, } & \text { filha do } \\
\text { rei da } & \text { Etiópia, } \\
\text { venerada } & \text { pelos } \\
\text { escravos e } & \text { seus } \\
\text { descendentes. } & \\
\end{array}$ \\
\hline 147 & $\begin{array}{l}\text { Plus tard, lorsque } \\
\text { la loi }{ }^{6} \text { fut signée, } \\
\text { les esclaves qui } \\
\text { travaillaient dans } \\
\text { les mines d'or et } \\
\text { de diamants } \\
\text { avaient créé leur } \\
\text { petite économie } \\
\text { propre et, } \\
\text { ensemble, avaient } \\
\text { construit un } \\
\text { salon, } \\
\text { précisément à } \\
\text { l'endroit où se } \\
\text { trouvait }\end{array}$ & la loi & $\begin{array}{l}\text { Loi d'Or, signée en } \\
1888, \text { qui abolit } \\
\text { officiellement } \\
\text { l'esclavage au Brésil. }\end{array}$ & $\begin{array}{l}\text { Lei Áurea, assinada em } \\
1888 \text {, que aboliu } \\
\text { oficialmente } \\
\text { escravidão no Brasil. }\end{array}$ \\
\hline
\end{tabular}


\begin{tabular}{|l|l|l|l|l|}
\hline & $\begin{array}{l}\text { cabanette de } \\
\text { torchis. }\end{array}$ & & & \\
\hline
\end{tabular}

Elaboração: as autoras

Como dito anteriormente, as notas contidas em Insoumises não são marcadas como notas de tradutor (N.T. ou N. do T.). Além disso, não têm numeração contínua no livro nem a cada conto. Em geral, a numeração reinicia por página, exceto nas páginas 146 e 147, em que a numeração é contínua. No conteúdo das notas, tampouco, a tradutora se manifesta como tal, podendo as notas serem entendidas também como notas de editor, acrescentadas após o processo tradutório. De toda forma, como Paula Anacaona é, ao mesmo tempo, tradutora e editora da obra traduzida, as notas podem ser entendidas como tal: notas de tradutor/editor. 0 primeiro recorte apresentado por Mittmann (2013), o das notas de "não-coincidência tradutor-autor", em que o tradutor inscreve a sua voz na nota de tradutor, não está presente no corpus. No segundo recorte apresentado por Mittmann, isto é, notas de "recorrência a outros discursos", as notas de Insoumises também não se encaixam, pois, para dar suas explicações de termos, personagens históricos e religiosos, a tradutora/editora não lançou mão de dicionários e outras obras de referência, pelo menos não explicitamente. As explicações são dadas com base no conhecimento da cultura brasileira por parte da tradutora/editora. Porém, parece-nos que o terceiro recorte apresentado por Mittmann em que o tradutor se apresenta em franco diálogo com o texto e/ou o autor, a saber, notas dando a perceber "embates durante o processo tradutório" e falta de equivalentes, está contemplado no corpus, na primeira e na segunda notas ("saudade" e "coronel", respectivamente). Na primeira nota, a tradutora manteve o termo em português, em itálico, fazendo um empréstimo, e deu uma explicação do termo na nota. Com isso, parece admitir que não existe na língua francesa um equivalente adequado para "saudade", como é usual se dizer. Na segunda nota, o termo é emprestado, mas sem itálico, marcando na nota que "coronel" aqui não se refere à hierarquia militar, o que explicaria o empréstimo e não a tradução pelo termo francês ("colonel”). As mesmas notas constam dos outros dois livros de Conceição Evaristo traduzidos pela mesma editora Anacaona, L'Histoire de Poncia (2015) e Banzo mémoires de la favela (2016). 
No geral, a percepção de Mittmann das notas de tradutor como um “discurso de extensão" produzido durante o processo tradutório (e, neste caso específico, talvez após o mesmo), mas com peculiaridades que diferem do discurso de base, isto é, o texto traduzido, é bastante pertinente ao caso estudado. Das treze notas, dez estão ligadas a termos e nomes próprios advindos da cultura afro-brasileira: santos (Nossa Senhora do Rosário, São Benedito e Santa Efigênia) e orixás (Zambi, Olorum, Exu, Ogum), cantoras e atrizes (Clementina de Jésus, Dona Ivone Lara, Lia de Itamaracá, Lea Garcia, Ruth de Souza), mães de santo (Mãe Menininha de Gantois, Mãe Meninazinha d'Oxum), uma escrava célebre tornada santa (Anastácia) e uma festa popular (congadas). Essas notas explicativas claramente "estendem" o sentido, guiando a interpretação dos leitores franceses, em geral, pouco conhecedores das referências culturais afro-brasileiras. Há ainda uma nota de cunho histórico (Lei Áurea), também ligada à escravidão no Brasil.

Relembrando as formulações teóricas de Aixelá (2013), todas as notas de Insoumises são referentes a itens culturais específicos. A tradutora/editora optou por fazer a explicação extratextual e não intratextual, talvez por achar que explicações intratextuais ficariam muito longas, quebrando o ritmo da frase e da leitura. Com isso, ela também aproveita para inserir mais referentes e explicações culturais nas notas, o que não faria em explicações intratextuais. É importante lembrar que essa estratégia da explicação, seja intratextual seja extratextual, é conservativa da referência cultural estrangeira, o que faz introduzir na cultura francesa referências exógenas, tirando o leitor de seu lugar de conforto. Barbosa (1990), como vimos anteriormente, classifica esse procedimento nos casos de divergência da realidade extralinguística, isto é, a realidade extralinguística francesa diverge da brasileira nos casos desses itens marcadamente culturais, o que parece fazer sentido no caso sob análise, em que a maioria das notas diz respeito à cultura afro-brasileira.

Vale lembrar que há referências culturais no texto para as quais não são chamadas notas de rodapé, como no trecho destacado nas páginas 146-147, em que "madame Laurinda Natividade, la professeure Efigenia Carlos, dona Iraci Graciano Fidelis" não recebem qualquer explicação, talvez porque a tradutora/editora não dispusesse delas. Parece então que a tradutora/editora 
apresenta explicações daquilo que já conhece na cultura brasileira, deixando as referências desconhecidas por ela (e por muitos leitores, inclusive brasileiros) sem explicação.

Talvez por coincidência, são treze mulheres retratadas, treze contos e treze notas de rodapé. É notável que a tradutora/editora tenha mantido itens culturais específicos brasileiros na tradução e tenha desejado estender essas referências culturais a explicações nas notas de rodapé, em uma atitude respeitosa ao universo afro-brasileiro. A existência de notas de tradutor/editor na edição estudada é, por si só, um sinal desse respeito. Contudo, a "função tradutor" não ficou bem clara nas notas, o que é menos louvável, dado que, por ser a tradutora também editora, provavelmente não teria sofrido as restrições de publicações de notas que os tradutores de modo geral sofrem e poderia ter exposto mais de sua subjetividade e de seus embates tradutórios dando a conhecer mais de seu projeto tradutório, nesse espaço tão almejado pelos tradutores e, ao mesmo tempo, tão negado a eles.

\section{Considerações finais}

É notável que uma escrita tão engajada e cheia de referências culturais específicas como a de Evaristo traga muitos desafios para a tradução. Insoumises, em sua versão francesa, busca respeitar uma ética da diferença e manter muitos elementos culturais específicos presentes no texto, principalmente aqueles que dizem respeito ao universo da cultura afrobrasileira. Embora o uso de paratextos do tradutor seja desejado, porém ainda restrito, elementos como notas de rodapé, por exemplo, podem funcionar como formas de explicar ao leitor da cultura de recepção a cultura do "outro", tirando o leitor da tradução de uma zona de conforto que faz com que ele leia textos traduzidos sem que perceba que está consumindo material proveniente de um outro contexto cultural, sendo assim um espaço de alteridade.

A análise dos paratextos de Insoumises, tradução francesa de Insubmissas lágrimas de mulheres, de Conceição Evaristo, neste artigo concentrada no 
índice e ordem de apresentação dos contos e nas notas de rodapé, revela que a edição francesa não pretende criar a ilusão de transparência que faz com que o leitor no polo de chegada encare a tradução como um "original", já que faz algumas "manipulações", entendidas aqui no sentido atribuído por Lefevere (2007), bem visíveis no texto de partida. Não só a ordem de apresentação dos contos é alterada, o que também altera a recepção dos contos por parte do leitor, que constrói um caminho de leitura diferente do leitor da obra de partida, quanto acrescenta notas de rodapé explicativas à tradução. Tais notas, como ressaltamos anteriormente, são notas de tradutora/editora, visto que Paula Anacaona exerce esses dois papeis na edição, alargando o espaço frequentemente exíguo para a inclusão de notas de tradutor. Respeitadora da diferença cultural e deixando sua marca clara de releitura e reescrita, Anacaona liga-se a Evaristo, para além da estrangeiridade, nessa escrita afrofeminina que torna cada vez mais a escritora conhecida e apreciada no exterior.

O presente trabalho foi realizado com apoio da Coordenação de Aperfeiçoamento de Pessoal de Nível Superior - Brasil (CAPES) - Código de Financiamento 001.

\section{Referências bibliográficas}

AIXELÁ, J. F. Itens culturais-específicos em tradução. Tradução de Mayara Matsu Marinho e Roseni Silva. In-Traduções, Florianópolis, v. 5, n. 8, pp. 185218, jan./jun., 2013.

Barbosa, H. G. Procedimentos técnicos da tradução: uma nova proposta. Campinas: Pontes, 1990.

BRITTO, P. H. As condições de trabalho do tradutor. Cadernos de Tradução, v.1, n.19, 2007, pp.193-204. Disponível em: https: / / periodicos.ufsc.br/index.php/traducao/article/view/6998/64 83. Acesso em: 26 jul. 2019.

CaRneiro, T. D. Contribuições para uma teoria do paratexto do livro traduzido: caso das traduções de obras literárias francesas no Brasil a partir de 
meados do século XX. 2014. 399f. Tese (Doutorado em Estudos da Linguagem) - Departamento de Letras, Pontifícia Universidade Católica do Rio de Janeiro, Rio de Janeiro, 2014.

DUKE, D. A. Traçando os rumos da nota de tradutor: o caso de 0 mundo se despedaça. Dissertação (Mestrado em Linguística Aplicada) - Instituto de Estudos da Linguagem. Unicamp, Campinas, 1993.

EVARISTO, C. Mulheres que escrevem entrevista: Conceição Evaristo. Mulheres que escrevem. Nov. 29, 2017. Disponível em: https://medium.com/mulheres-que-escrevem/mulheres-queescrevem-entrevista-conceicao-evaristo-fa243ff84284. Acesso em: 06 jul. 2020. . Insubmissas lágrimas de mulher. Belo Horizonte: Nandyala, 2011. . Insubmissas lágrimas de mulheres. 2. ed. Rio de Janeiro: Malê, 2016. . Insoumises. Tradução: Paula Anacaona. Paris: Anacaona, 2016.

HINOJOSA, F. R.; LIMA, R. A tradução como estratégia de interculturalidade no ensino de língua estrangeira. Bocc: Biblioteca On-line de Ciências da Comunicação, v. 1, pp. 1-10, 2008. Disponível em: www.bocc.ubi.pt/pag/lima-hinojosa-traducao-estrategiainterculturalidade.pdf. Acesso em: 02 jan. 2021.

FLORES, V. N.; HOFF, S. L. Os tradutores e a tradução: o paratexto como lugar de reflexão sobre o sentido na linguagem. Revista Ecos, v. 25, Ano 15, n. 2, 2018, pp. 351-373.

GenetTE, G. Paratextos editoriais. Tradução: Álvaro Faleiros. Cotia, SP: Ateliê Editorial, 2009.

GUEDES, D. Conheça a Anacaona, a editora francesa especializada em literatura brasileira. Jornal do Commercio online. Cultura. Publicado em 10/05/2015. Disponível em: https://jc.ne10.uol.com.br/canal/cultura/literatura/noticia/2015/05 /10/conheca-a-anacaona-a-editora-francesa-especializada-emliteratura-brasileira-180437.php. Acesso em: 02 jan. 2021.

Itaú CultuRAL (2017). Exposição Ocupação Conceição Evaristo. 34 edição. Lambert, J.; VAn Gorp, H. On Describing Translations. In: Hermans, T. (ed.) The Manipulation of Literature: Studies in Literary Translation. Londres 
and Sydney: Croom Helm, 1985.

LEFEVERE, A. Tradução, reescrita e manipulação da fama literária. Tradução: Claudia Matos Seligmann. Bauru, SP: Edusc, 2007.

MITTMANN, S. Notas do tradutor e processo tradutório: análise e reflexão sob uma perspectiva discursiva. Porto Alegre: Ed. da UFRGS, 2003.

SeXTANTE. Manual Sextante. 33p.

VenUtI, L. A invisibilidade do tradutor. Tradução: Carolina Alfaro. paLavra, 3, pp. 111- 134, 1996.

- Escândalos da tradução: por uma ética da diferença. Tradução:

Laureano Pelegrini, Lucinéia Marcelino Villela, Marileide Dias Esqueda e Valéria Biondo. Bauru-SP: EDUSC, 2002.

WYLER, L. Línguas, poetas e bacharéis: uma crônica da tradução no Brasil. Rio de Janeiro: Rocco, 2003.

ZoLIN, L. O. Literatura de autoria feminina. In: ; Bonnici, T. (orgs.) Teoria Literária: abordagens históricas e tendências contemporâneas. Maringá: Eduem, 2009, pp.327-336. 